\title{
Influence of dietary fiber on macrostructure and processing traits of extruded dog foods
}

\author{
M. Monti ${ }^{\text {a }}$, M. Gibson ${ }^{b}$, B.A. Loureiro ${ }^{a}$, F.C. Sá ${ }^{a}$, T.C. Putarov ${ }^{a}$, C. Villaverde $^{c}$, S. \\ Alavi $^{\text {b }}$, A.C. Carciofi ${ }^{\mathrm{a}, *}$ \\ a Departamento de Clínica e Cirurgia Veterinária, Campus de Jaboticabal, UNESP - Univ Estadual Paulista, São Paulo, Brazil \\ b Department of Grain Science and Industry, Kansas State University, Manhattan, KS, USA \\ c Departament de Ciència Animal y dels Aliments, Universitat Autònoma de Barcelona, Campus UAB, Bellaterra, Barcelona, Spain
}

\section{A R T I C L E I N F O}

\section{Article history:}

Received 1 February 2016

Received in revised form 11 July 2016

Accepted 13 July 2016

\section{Keywords:}

Extrusion

Fiber sources

Guava

Particle size

Sugarcane

Wheat bran

\begin{abstract}
A B S T R A C T
Fiber is currently used in dog food formulations due to its nutritional properties. However, few studies have evaluated the influence of fiber on the extrusion traits and kibble formation. The present study evaluated the effect of fiber type and particle size on extrusion processing parameters and kibble macrostructure of dog foods. In treatment 1, guava fiber was added to a control formula (CO) at different inclusion levels: 3\% (GF3), 6\% (GF6), and $12 \%$ (GF12). In treatment 2, two fiber types (sugarcane and wheat bran) and two fiber particle sizes were compared to a control ( $\mathrm{CO}$ ) product. Foods were manufactured using a single screw extruder. Each food was processed on two separate days and samples were collected four times per run, for a total of eight replications per diet. The processing conditions were not changed for any treatment. Data were analyzed via analysis of variance, and compared by polynomial contrasts for treatment 1 , and by defined orthogonal contrasts for treatment $2(\mathrm{P}<0.05)$. Guava fiber inclusion resulted in a linear increase in temperature, pressure, and specific mechanical energy (SME) input $(\mathrm{P}<0.001)$ during extrusion, whereas starch cooking (assessed by the amyloglucosidase method) and radial expansion decreased linearly $(\mathrm{P}<0.001)$. Kibble density and cutting force increased linearly $(\mathrm{P}<0.001)$ with guava fiber inclusion. In treatment 2 , fiber addition also increased SME $(\mathrm{P}<0.001)$ and decreased radial expansion $(\mathrm{P}=0.008)$. However the latter was compensated by an increase in longitudinal expansion in the case of sugarcane fiber, resulting in no change in kibble density. Cutting force was higher $(\mathrm{P}<0.001)$ for fiber supplemented foods, similar to treatment 1 , but sugarcane fiber had a higher impact on hardness than wheat bran $(\mathrm{P}<0.001)$. The finely ground fibers led to higher starch gelatinization $(P<0.05)$ and kibbles with lower piece density $(P=0.018)$. To summarize, insoluble fibers such as guava fiber, sugarcane and wheat bran at high inclusion rate increase the electric energy required to extrude, may reduce starch cooking and result in the production of less expanded, denser and harder kibbles. However, kibble characteristics are also significant impacted by fiber type and particle size.
\end{abstract}

(C) 2016 Elsevier B.V. All rights reserved.

Abbreviations: CO, control diet without added fiber source; CP, crude protein; DM, dry matter; GF3, diet with the addition of 3\% guava fiber; GF6, diet with the addition of $6 \%$ guava fiber; GF12, diet with the addition of $12 \%$ guava fiber; OM, organic matter; SAS, Statistical Analysis Systems; $\mathrm{SF}_{\mathrm{L}}$, diet with sugarcane fiber large particles; $\mathrm{SF}_{\mathrm{S}}$, diet with sugarcane fiber small particles; SME, specific mechanical energy; STE, specific thermal energy; TSE, total specific energy; $\mathrm{WB}_{\mathrm{L}}$, diet with wheat bran large particles; $\mathrm{WB}_{\mathrm{S}}$, diet with wheat bran small particles.

* Corresponding author.

E-mail address: aulus.carciofi@gmail.com (A.C. Carciofi). 
Table 1

Chemical composition of the fiber sources used in the experiment. Values in $\mathrm{g} / \mathrm{kg}$ on as-fed basis. ${ }^{\mathrm{b}}$

\begin{tabular}{|c|c|c|c|}
\hline \multirow[t]{2}{*}{ Item } & \multicolumn{3}{|c|}{ Fiber sources ${ }^{a}$} \\
\hline & Guava fiber & Sugarcane fiber & Wheat bran \\
\hline Moisture & 93.1 & 57.0 & 71.1 \\
\hline Protein & 32.4 & 29.4 & 163.8 \\
\hline Starch & 68.1 & 6.5 & 249.3 \\
\hline Fat & 22.8 & 11.2 & 47.1 \\
\hline Total dietary fiber & 702.6 & 869.9 & 395.2 \\
\hline Insoluble fiber & 689.0 & 869.9 & 378.0 \\
\hline Soluble fiber & 13.6 & 0.0 & 17.2 \\
\hline Cellulose & 361.0 & 458.1 & 71.8 \\
\hline Hemicellulose & 173.3 & 281.9 & 290.3 \\
\hline Lignin & 113.4 & 93.0 & 46.7 \\
\hline
\end{tabular}

a All fiber sources were provided by Dilumix, Leme, SP, Brazil.

b Analyzed in duplicate.

\section{Introduction}

During extrusion to make dog food, a combination of moisture, shear, temperature, and pressure are applied, in a continuous and short process that ends with forcing the material through a specifically designed opening (Riaz, 2000). The process induces changes in food ingredients, resulting in extensive cooking and a plasticized food dough (Altan et al., 2008; Yağci and Gögüss, 2008). These modifications are directly linked to and depend on the total energy transferred to the dough, composed of mechanical and thermal energy as measured by the specific mechanical energy (SME) and specific thermal energy (STE) input, respectively. The combination of these two types of energy promotes starch gelatinization, protein denaturation, lipid modification, enzyme inactivation, and reduction of microbial viability. At the end of the extruder barrel, the plasticized dough expands in contact with atmosphere, creating a particular kibble macrostructure that affects shape and texture (Griffin, 2003; Challacombe et al., 2011).

Fiber supplemented extruded foods are produced nowadays by most pet food companies. Fiber is used to dilute energy density promoting specific benefits related to gut and general health (Kawauchi et al., 2011; Fischer et al., 2012). Inclusion of fiber sources, however, influences the processing parameters, SME and possibly STE as well, potentially altering the final product characteristics (Mendonça et al., 2000). Dietary fiber is a highly structured and unexpandable material with variable water absorption capacity; that can affect viscosity, mass flow inside the barrel, and formation of cellular structure in the extrudates (Karkle et al., 2012a). Due to this, kibble expansion and important textural characteristics such as hardness and crispness may be altered by fiber (Karkle et al., 2012a), thus changing the sensory attributes and palatability (Koppel et al., 2015).

Detailed information about the impact of fiber on extrusion traits and kibble macrostructure is only available for human foods (Brennan et al., 2008; Baik et al., 2004; Karkle et al., 2012b). Characteristics of the specific fibrous material included in the formula also have an impact on extrusion traits, and thus fiber effects cannot be generalized. Fruit and vegetable processing by-products have been studied in extruded foods for humans (Upadhyay et al., 2010; Karkle et al., 2012a), as a way to add value and to minimize the environmental impact of these residues (Altan et al., 2008). Besides fiber type, its particle size is also important. It is possible to change dynamics of the extrusion process and kibble structure formation by changing the fiber particle length. Understanding these effects could be important to achieve better cooking, reduce extrusion cost, and overcome some negative effects of fiber on extrudate macrostructure. Palatability and digestibility issues are concerns when fiber is added to dog foods; it is possible that some of these possible negative effects could be related to reduced efficiency of the extrusion process. However, there is no data regarding the effect of fiber particle size on the extrusion of dog foods.

The present study aimed to evaluate the influence of increasing amounts of guava fiber (treatment 1) and sugarcane and wheat bran fiber of two different particle sizes (treatment 2) on the extrusion traits and kibble macrostructure of dog foods.

\section{Material and methods}

\subsection{Fiber ingredients and diet formulation}

Two separate treatments were conducted, the first treatment was designed to study the inclusion level of guava fiber (Psidium guajava) and the second one to assess the impact of sugarcane fiber and wheat bran particle sizes. Guava fiver is a by-product of guava juice extraction, produced from drying and grinding the solid residues after removal of all solubles. Its composition includes the insoluble material of the pericarp and the seeds. Sugarcane fiber is obtained from sugarcane bagasse, which is washed and centrifuged to remove residual sugars and minerals, and afterwards dried and micronized. The company Dilumix (Leme, Sao Paulo, Brazil) provided the fiber ingredients used in the study. The chemical composition of the fibers is provided in Table 1. 
Table 2

Ingredient and chemical composition of dog foods using different fiber sources.

\begin{tabular}{|c|c|c|c|c|c|c|}
\hline \multirow[t]{2}{*}{ Item } & \multicolumn{6}{|c|}{ Foods $\mathrm{s}^{\mathrm{a}}$} \\
\hline & $\mathrm{CO}$ & GF3 & GF6 & GF12 & SC & WB \\
\hline \multicolumn{7}{|c|}{ Ingredient composition (g/kg, as-fed basis) } \\
\hline Maize & 579.7 & 548.3 & 517.9 & 450.9 & 473.3 & 305.5 \\
\hline Poultry by product meal & 318.0 & 318.6 & 318.2 & 325.2 & 325.6 & 261.2 \\
\hline Poultry fat & 64.4 & 65.2 & 66.0 & 66.0 & 73.2 & 76.4 \\
\hline Guava fiber ${ }^{b}$ & - & 30.0 & 60.0 & 120.0 & - & - \\
\hline Sugarcane fiber ${ }^{c}$ & - & - & - & - & 90.0 & - \\
\hline Wheat bran $^{\mathrm{d}}$ & - & - & - & - & - & 320.0 \\
\hline Fish oil & 1.5 & 1.5 & 1.5 & 1.5 & 1.5 & 1.5 \\
\hline Palatant enhancer ${ }^{\mathrm{e}}$ & 20 & 20 & 20 & 20 & 20 & 20 \\
\hline Sodium chloride & 5 & 5 & 5 & 5 & 5 & 5 \\
\hline Potassium cholide & 5 & 5 & 5 & 5 & 5 & 5 \\
\hline Vitamin and mineral mix ${ }^{f}$ & 3 & 3 & 3 & 3 & 3 & 3 \\
\hline Choline chloride & 2 & 2 & 2 & 2 & 2 & 2 \\
\hline Antioxidant $^{\mathrm{g}}$ & 0.4 & 0.4 & 0.4 & 0.4 & 0.4 & 0.4 \\
\hline Mold inhibitor $^{\mathrm{h}}$ & 1 & 1 & 1 & 1 & 1 & 1 \\
\hline \multicolumn{7}{|c|}{ Analyzed chemical composition of the final extruded product ( $\mathrm{g} / \mathrm{kg}$, DM-basis) } \\
\hline Moisture & 59.0 & 68.0 & 60.0 & 73.0 & 58.0 & 58.6 \\
\hline Ash & 60.0 & 55.7 & 66.2 & 61.0 & 56.8 & 61.0 \\
\hline Crude protein & 252.1 & 257.7 & 259.5 & 251.7 & 254.8 & 252.1 \\
\hline Crude fat & 153.0 & 159.0 & 152.0 & 146.1 & 148.7 & 150.2 \\
\hline Total dietary fiber & 107.5 & 131.3 & 166.3 & 183.6 & 166.1 & 180.0 \\
\hline Insoluble dietary fiber & 107.5 & 128.5 & 163.7 & 176.9 & 166.1 & 171.7 \\
\hline Soluble dietary fiber & 0.0 & 2.8 & 2.7 & 6.7 & 0.0 & 8.4 \\
\hline Starch & 412.0 & 387.0 & 357.0 & 357.0 & 379.1 & 344.0 \\
\hline
\end{tabular}

a $\mathrm{CO}=$ control food, without added fiber source, GF3 = addition of 3\% guava fiber, GF6 = addition of $6 \%$ guava fiber, GF12=addition of $12 \%$ guava fiber, $\mathrm{SC}=$ addition of sugarcane fiber, $\mathrm{WB}=$ addition of wheat bran fiber

b Dilufiber Guava, Dilumix, Leme, SP, Brazil.

c Vit2be Fiber, SPF do Brazil, Descalvado, Brazil.

d Wheat bran fiber, Dilumix, Leme, SP, Brazil.

e Liquid Palatant, SPF do Brazil, Descalvado, Brazil.

${ }^{\mathrm{f}}$ Added per kg of food: iron, $120 \mathrm{mg}$; copper, $15 \mathrm{mg}$; magnesium, $75 \mathrm{mg}$; zinc, $150 \mathrm{mg}$; iodine, $2 \mathrm{mg}$; selenium, $0.3 \mathrm{mg}$; vitamin A, 18,000 IU; vitamin D3, $1000 \mathrm{IU}$; vitamin E, $100 \mathrm{IU}$; vitamin K, $2 \mathrm{mg}$; biotin, $0.6 \mathrm{mg}$; thiamine. $20 \mathrm{mg}$; riboflavin, $10 \mathrm{mg}$; pantothenic acid, $50 \mathrm{mg} ;$ niacin, $75 \mathrm{mg}$; vitamin B6, $6 \mathrm{mg}$; folic acid, $4 \mathrm{mg}$; vitamin B12, $0.1 \mathrm{mg}$.

g Banox: butylated hydroxyanisole, butylated hydroxytoluene, propyl gallate and calcium carbonate. Alltech do Brasil Agroindustrial Ltda.

${ }^{\text {h }}$ Mold Zap: Ammonium dipropionate, acetic acid, sorbic acid and benzoic acid. Alltech do Brasil Agroindustrial Ltda.

A control formula (CO) containing maize and poultry by-product meal, and with no fiber source addition, was developed for adult dogs according to the European Pet Food Industry Federation Nutritional Guidelines (FEDIAF, 2013). The fiber sources were added to the $\mathrm{CO}$, replacing maize to create four formulations in treatment 1 , the control formula plus three addition amounts of guava fiber at the same particle size (GF): $3 \%$ (GF3), $6 \%$ (GF6), and $12 \%$ (GF12). The guava fiber had a mean particle size of $213 \mu \mathrm{m}$, and was used to evaluate the effect of increased amounts of an angiosperm pericarp derived fiber source. In treatment 2 the same control formulation was used, and sugarcane fiber or wheat bran with two different particle sizes was added (Table 2). The same lot of raw fiber material was ground to obtain four different ingredients: large sugarcane fiber $\left(\mathrm{SF}_{\mathrm{L}}\right)$, small sugarcane fiber $\left(\mathrm{SF}_{\mathrm{S}}\right)$, large wheat bran $\left(\mathrm{WB}_{\mathrm{L}}\right)$, and small wheat bran $\left(\mathrm{WB}_{\mathrm{S}}\right)$; with a mean size of $395 \mu \mathrm{m}$, $197 \mu \mathrm{m}, 345 \mu \mathrm{m}$, and $143 \mu \mathrm{m}$, respectively. Treatment 2 was designed to evaluate the particle size effect of filamentous fibers, derived from plant stalk (sugarcane) or seed pericarp (wheat bran). The particle sizes were determined using laser diffraction particle size analysis (Boac et al., 2009). The total dietary fiber content of all ingredients was determined before diet formulation and the foods containing sugarcane fiber and wheat bran were formulated to have approximately $16 \%$ of total dietary fiber, with the fiber sources again replacing maize along with some adjustments for poultry by product meal and poultry fat. This inclusion amount was established based on the dietary fiber content of the high fiber foods available for dogs in the market, that vary between $14 \%$ to $20 \%$ of dietary fiber.

\subsection{Diet preparation}

The ingredients, with the exception of fiber sources, were weighed, mixed, and ground using a hammer mill fitted with a screen sieve size of $0.8 \mathrm{~mm}$ (Sistema Tigre de Mistura e Moagem, Tigre, Sao Paulo, Brazil). The fiber source was added and mixed, compounding the final food.

Foods were extruded in a single screw extruder (MEX 250, Manzoni, Campinas, Brazil), with a processing capacity of $250 \mathrm{~kg} / \mathrm{h}$, screw diameter of $80 \mathrm{~mm}$, and die diameter of $4.5 \mathrm{~mm}$ (resulting in die open area of $15.9 \mathrm{~mm}^{2}$ ). The extruded screw has five sections: initial - single flight and no steam lock; second - single flight and small steam lock; third - double flight uncut and small steam lock; fourth - double flight uncut and medium steam lock; fifth - double flight cut cone. The 
preconditioner shaft speed was set $40 \mathrm{rpm}$. Thermal energy was implemented on the dough at preconditioner by direct steam infusion. For all treatments, the extruder screw speed was set to $465 \mathrm{rpm}$. Raw material was fed into the preconditioner using a volumetric delivery system at a rate of $107-144 \mathrm{~kg} / \mathrm{h}$. Water was injected into the preconditioner at a rate of $15-22 \mathrm{~kg} / \mathrm{h}$. Thermal energy was provided to mash inside the preconditioner by direct steam infusion, resulting in preconditioner exit temperature in the range of $80-90^{\circ} \mathrm{C}$. No water or steam was injected into the extruder barrel.

Each food was processed separately on two different days for replicates. Each day the production was started with a high fiber diet to stabilize the equipment and establish the basal processing conditions. After stabilization of the equipment (minimum of $45 \mathrm{~min}$ ), the processing was kept constant and no alterations were done on any of the independent process parameters (feeder screw speed, extruder screw speed, water and steam injection valve settings, and cutting knife speed). After this moment, production parameters were recorded every $15 \mathrm{~min}$, with at least four measurements per diet and day, totaling eight observations per diet. The parameters registered were: preconditioner exit temperature, engine amperage, dough temperature before die, dough temperature at extruder exit, dough pressure before die, extruder output mass, water injection rate, bulk density after extruder, and bulk density after dryer. Other parameters recorded included ambient room temperature, working water temperature, mash feed temperature, and steam pressure. At each observation time, food samples were collected from the preconditioner, the extruder and the dryer and stored at $-20^{\circ} \mathrm{C}$ for further analysis. After extrusion, the kibbles were dried in a forced air dryer at $105^{\circ} \mathrm{C}$ for $20 \mathrm{~min}$, and coated with poultry fat and liquid palatant (D’TECH 6L, SPF, Descalvado, São Paulo, Brazil).

\subsection{Chemical analysis}

Food samples were ground in a cutting mill (Mod MA-350, Marconi, Piracicaba, Brazil) fitted with a $1 \mathrm{~mm}$ screen. The samples were analyzed by oven-drying for dry matter (DM) (method 934.01), by muffle furnace incineration for ash content (method 942.05), by the Kjeldahl method for crude protein (method 954.01), and with a Soxhlet apparatus extraction for acid hydrolysed ether extract (method 954.02), following the methods described by the Association of Official Analytical Chemists (AOAC, 1995). Organic matter (OM) of the samples was calculated as DM minus ash. Dietary fiber (total, soluble, and insoluble) was measured by using a combination of enzymatic and gravimetric procedures (method 991.43, AOAC, 1995), Starch content was determined according to the method of Hendrix (1993), and the gelatinization degree was measured by the amyloglucosidase method as described by Sá et al. (2013).

Fiber sources were analyzed additionally for neutral detergent fiber (aNDFom), using $\alpha$-amylase and without the addition of sodium sulphite, acid detergent fiber (ADFom) and acid detergent lignin (ADL) by solubilization of cellulose with 72\% sulfuric acid, according to Van Soest et al. (1991). The cellulose content was calculated subtracting lignin from the ADFom values, and hemicellulose content were calculated subtracting ADFom from aNDFom.

\subsection{Kibble traits and macrostructure}

The extrudate cutting force was measured for 20 kibbles per diet. Kibbles were first stabilized at the same moisture in an oven (ETS Modelo 532, Systens Eletro-Tech, Inc., Glenside, PA, EUA) at $35^{\circ} \mathrm{C}$ during 24 h. Individual kibbles were weighted and the cutting force determined with a texturometer (Texture Analyser TAX/T2I - Stable Micro Systems Ltda, Godalming, UK) equipped with a load cell of $50 \mathrm{kgf}$. The samples were tested with a $10 \mathrm{~mm}$ penetration distance and speed of $2.0 \mathrm{~mm} / \mathrm{s}$, using a Warner Bratzler Knife. To ensure that the samples were representative, each test kibble was selected so its diameter corresponded to the average diameter measured for the treatment.

Electronic micrographs of the kibbles were obtained in a scanning field emission scanning electron microscope (JEOL, JSM-7500F; Miaka, Tokyo, Japan), adjusted to $20 \mathrm{kV}$. Images were evaluated by a trained examiner, blinded to the experimental groups. The analysis were performed in the Chemistry Institute, UNESP (Araraquara campus). All image analysis was qualitative and not submitted to statistical evaluation. Images of the external and internal surface were evaluated. For the internal evaluation, kibbles were cut along the medial direction. Pictures of the internal surface were processed with standardized filter sets using the software Adobe Photoshop CC 2015 (Adobe Systems, California, USA) and the total area of inner cells measured. The results were expressed as the percentage of cell area relative to mean kibble cross sectional area, using the following formula:

$$
\text { Percentage of cell areas }=\frac{\text { Total area of inner cells measured }}{\text { Mean kibble cross sectional area }}
$$

For each treatment, the length (le), diameter (de) and mass (me) of 20 extrudates were measured and used to obtain the radial expansion ratio $(\mathrm{RE})$, specific length $\left(1_{\mathrm{sp}}\right)$ and piece density $(\rho)$, as described below.

$$
\begin{aligned}
& \mathrm{RE}=\frac{\mathrm{d}_{\mathrm{e}}{ }^{2}}{\mathrm{~d}_{\mathrm{d}}{ }^{2}} \\
& \mathrm{l}_{\mathrm{sp}}=\frac{\mathrm{le}}{\mathrm{me}}(\mathrm{mm} / \mathrm{g})
\end{aligned}
$$




$$
\rho=\frac{4 \mathrm{me}}{\pi \times d e^{2} \times \mathrm{le}}\left(\mathrm{kg} / \mathrm{m}^{3}\right)
$$

where: $d_{d}=$ die diameter.

\subsection{Specific mechanical energy and specific thermal energy calculations}

The SME (kW-h/ton) was calculated for each treatment in accordance with Riaz (2007), with the following formula:

$$
\mathrm{SME}=\frac{(\sqrt{3} \times \text { Voltage } \times(\mathrm{WA}-\mathrm{EA}) \times(\operatorname{cosFi} \div 1000)) \times 1000}{\text { Throughput }}
$$

Where;

Voltage $=(220 \mathrm{~V})$.

$W A=$ working amperage or the motor amperage during processing $(A)$.

$\mathrm{EA}=$ motor no load amperage $(\mathrm{A})$.

$\cos \mathrm{Fi}=$ power factor $(0.76)$.

Throughput $=$ raw material feed rate into the preconditioner $(\mathrm{t} / \mathrm{h})$.

The STE $(\mathrm{kW}-\mathrm{h} / \mathrm{t})$ was calculated as the net thermal energy contributed via steam absorption by mash inside the preconditioner divided by the raw material throughput $(\mathrm{t} / \mathrm{h})$. The net steam absorption $(\mathrm{kg} / \mathrm{h})$ was calculated from mass balance according to Riaz (2000), and corresponding thermal energy was calculated by multiplying by the steam enthalpy $(\mathrm{kJ} / \mathrm{kg}$ ) from steam tables and adjusting for average mash temperature inside the preconditioner.

The Total Specific Energy (TSE; kW-h/t) was obtained by the sum of the SME and STE.

\subsection{Statistical analysis}

Each treatment was analyzed separately. Both studies follow a randomized block design, with two blocks (days of extrusion) and four repetitions per block (each 15 min interval of sampling), totaling eight repetitions per treatment. The experimental unit was considered the diet sampling, except for kibble macrostructure and deforming force, when the experimental unit was one kibble (with 20 repetitions per treatment). Data were submitted to analysis of variance, model sums of squares were separated into treatment (diet) and block (days of extrusion) effects. When differences were found on $\mathrm{F}$ test, in treatment 1 polynomial contrasts were used to evaluate the inclusion levels of guava fiber, and in treatment 2 orthogonal contrasts were used to detect differences between: control and fiber supplemented foods (CO versus $\left.\mathrm{SF}_{\mathrm{L}}+\mathrm{SF}_{\mathrm{S}}+\mathrm{WB}_{\mathrm{L}}+\mathrm{WB}_{S}\right)$; sugarcane and wheat bran fibers $\left(\mathrm{SF}_{\mathrm{L}}+\mathrm{SF}_{\mathrm{S}}\right.$ versus $\left.\mathrm{WB}_{\mathrm{L}}+\mathrm{WB}_{\mathrm{S}}\right)$; fiber particle sizes $\left(\mathrm{SF}_{\mathrm{L}}+\mathrm{WB}_{\mathrm{L}}\right.$ versus $\left.\mathrm{SF}_{\mathrm{S}}+\mathrm{WB}_{\mathrm{S}}\right)$. The mixed procedure of SAS statistical software (version 9.1; SAS Institute, 2008 Cary, NC, USA) was used to perform the analysis. All data were found to comply with ANOVA assumptions. The $\alpha$ level of significance was set at 0.05 .

\section{Results}

\subsection{Treatment 1}

During extrusion the preconditioner temperature $(\mathrm{P}<0.001)$ and output moisture $(\mathrm{P}=0.005)$ decreased linearly as guava fiber inclusion increased (Table 3). The mass flow out of the preconditioner (calculated by using mass balance) fluctuated randomly. Starch gelatinization after preconditioner was similar among foods, with a mean value of approximately $33 \%$ $(\mathrm{P}>0.05)$. The motor load (engine amperage), and die temperature and pressure increased linearly with guava fiber inclusion $(P<0.001)$. Extruder output mass varied according to the preconditioner mass flow $(P=0.003)$. SME input increased almost three-fold when comparing CO with GF12 $(\mathrm{P}<0.001)$. STE input increased linearly $(\mathrm{P}=0.025)$, which together with SME resulted in linear increase in TSE $(\mathrm{P}<0.001)$. Because the SME presented greater proportional increase than STE, the STE:SME ratio also decreased linearly $(P<0.001)$. The addition of guava fiber reduced linearly the kibble radial expansion rate and starch gelatinization $(P<0.001)$, and increased the piece density $(P<0.001)$. Fiber inclusion resulted in a quadratic reduction in kibble specific length $(\mathrm{P}<0.001)$, whereas it resulted in an increased kibble hardness, as verified by the linear increase on cutting force $(\mathrm{P}<0.005)$. Fig. 1 illustrates internal and external pictures of the kibbles produced in treatment 1 . It was possible to note that the cellular structure in the CO diet was composed of larger cells compared to the GF12 food. The percentage of cell area in relation to total kibble diameter area was $15.3 \%$ for CO, and decreased to $13.4 \%$ for GF3, $13.0 \%$ for GF6, and $12.6 \%$ for GF12. Unfortunately, only a qualitative evaluation of the images was performed, and it was not possible to perform a statistical evaluation of these results. It is possible to see bigger pores on the kibble surface of the CO food compared to GF3 and GF6 foods, whereas the kibbles of the GF12 food showed an uneven and rough surface. 
Table 3

Processing parameters and kibble macrostructure traits of extruded dog foods with different inclusions of guava fiber. Experiment 1.

\begin{tabular}{|c|c|c|c|c|c|c|c|}
\hline \multirow[t]{2}{*}{ Item } & \multicolumn{4}{|l|}{ Foods ${ }^{a}$} & \multirow[t]{2}{*}{ SEM. ${ }^{b}$} & \multicolumn{2}{|c|}{ Contrast $^{\mathrm{C}}$} \\
\hline & $\mathrm{CO}$ & GF3 & GF6 & GF12 & & Linear & Quadratic \\
\hline \multicolumn{8}{|l|}{ Preconditioner } \\
\hline Temperature $\left({ }^{\circ} \mathrm{C}\right)$ & 85.6 & 84.4 & 85.7 & 82.2 & 0.59 & $<0.001$ & 0.301 \\
\hline Output moisture (\%) & 27.7 & 26.1 & 25.7 & 25.2 & 0.01 & 0.005 & 0.577 \\
\hline Output mass (as-fed, kg/h) & 181.9 & 170.2 & 162.8 & 190.8 & 2.31 & 0.004 & 0.005 \\
\hline Starch gelatinization (\%) & 35.6 & 30.3 & 33.6 & 33.5 & 1.28 & 0.987 & 0.756 \\
\hline \multicolumn{8}{|l|}{ Extruder } \\
\hline Engine amperage (A) & 42.1 & 42.80 & 46.6 & 49.18 & 0.70 & $<0.001$ & 0.160 \\
\hline Die temperature $\left({ }^{\circ} \mathrm{C}\right)$ & 125.8 & 130.3 & 141.3 & 134.3 & 1.46 & $<0.001$ & 0.137 \\
\hline Die pressure (bar) & 61.7 & 61.7 & 70.3 & 70.6 & 0.88 & $<0.001$ & 0.909 \\
\hline Output mass (as-fed, kg/h) & 170.4 & 161.2 & 149.6 & 153.2 & 3.32 & 0.043 & 0.003 \\
\hline \multicolumn{8}{|l|}{ Energy balance (kW-h/ton) } \\
\hline $\mathrm{SME}^{\mathrm{d}}$ & 14.1 & 14.0 & 28.3 & 35.4 & 2.94 & $<0.001$ & $<0.001$ \\
\hline $\mathrm{STE}^{\mathrm{e}}$ & 61.0 & 58.1 & 72.9 & 73.8 & 2.80 & 0.025 & 0.678 \\
\hline $\mathrm{TSE}^{\mathrm{f}}$ & 75.1 & 72.1 & 101.2 & 109.2 & 5.32 & $<0.001$ & 0.328 \\
\hline STE:SME & 4.32 & 4.15 & 2.58 & 2.08 & 0.37 & $<0.001$ & 0.371 \\
\hline \multicolumn{8}{|l|}{ Kibble traits (After Dryer) } \\
\hline Starch gelatinization (\%) & 92.8 & 91.1 & 90.5 & 88.3 & 0.93 & $<0.001$ & 0.823 \\
\hline Piece density $\left(\mathrm{kg} / \mathrm{m}^{3}\right)$ & 0.37 & 0.40 & 0.42 & 0.43 & 0.01 & $<0.001$ & 0.190 \\
\hline Radial expansion rate & 4.1 & 3.9 & 3.5 & 3.2 & 0.05 & $<0.001$ & 0.263 \\
\hline Specific length (mm/g) & 47.4 & 40.8 & 41.6 & 46.3 & 0.37 & 0.097 & $<0.001$ \\
\hline Cutting force (kg.f) ${ }^{g}$ & 2.4 & 2.9 & 3.1 & 3.4 & 0.06 & $<0.005$ & 0.263 \\
\hline
\end{tabular}

a $\mathrm{CO}=$ control food, without added fiber source, GF3 = addition of $3 \%$ guava fiber, GF6 = addition of $6 \%$ guava fiber, GF12=addition of $12 \%$ guava fiber.

b $\mathrm{SEM}=$ standard error of the mean $(n=32)$.

c Linear and quadratic effect of guava fiber additions.

d $\mathrm{SME}=$ specific mechanical energy.

e $\mathrm{STE}=$ specific thermal energy.

f $\mathrm{TSE}=$ total specific energy.

g $n=20$ kibbles per food.
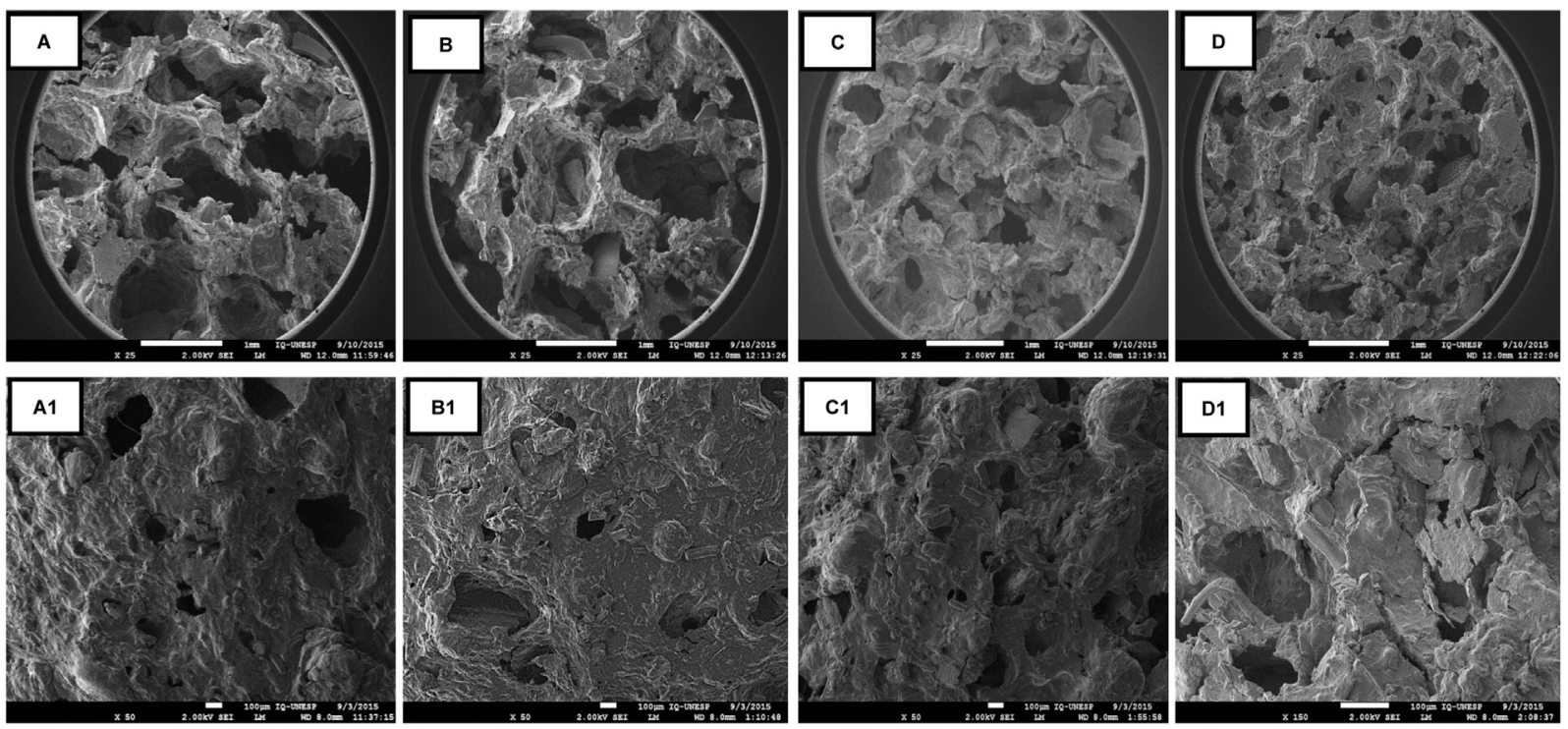

Fig. 1. Scanning electron micrograph of kibbles produced with different inclusions of guava fiber on experiment 1 . A, B, C and D correspond to the internal area of the CO, GF3, GF6 and GF12 foods, respectively. Increase of 25×. A1, B1, C1 and D1 correspond to the external surface of the CO, GF3, GF6 and GF12 foods, respectively. Increase of $50 \times . \mathrm{CO}=$ control foods, without added fiber source; GF3 = addition of $3 \%$ guava fiber; GF6 = addition of $6 \%$ guava fiber; GF12 $=$ addition of $12 \%$ guava fiber.

\subsection{Treatment 2}

The parameters measured at preconditioner did not change in treatment 2, with the exception of the output mass of the preconditioner, which was lower for the fiber supplemented foods in comparison with the CO diet $(P=0.007$; Table 4). The motor amperage was lower for sugarcane fiber than wheat bran foods, and lower for the small particle size than large 
Table 4

Processing parameters and kibble macrostructure traits of extruded dog foods with different types and particle sizes of fiber. Experiment 2.

\begin{tabular}{|c|c|c|c|c|c|c|c|c|c|}
\hline \multirow[t]{2}{*}{ Item } & \multicolumn{5}{|l|}{ Foods $^{\mathrm{a}}$} & \multirow[t]{2}{*}{$\mathrm{SEM}^{\mathrm{b}}$} & \multicolumn{3}{|l|}{ Contrasts } \\
\hline & $\mathrm{CO}$ & $\mathrm{SF}_{\mathrm{L}}$ & $\mathrm{SF}_{\mathrm{S}}$ & $\mathrm{WB}_{\mathrm{L}}$ & $\mathrm{WB}_{\mathrm{S}}$ & & $\mathrm{SF} \times \mathrm{WB}^{\mathrm{c}}$ & Large $x$ Small ${ }^{\mathrm{d}}$ & CO x Fiber ${ }^{\mathrm{e}}$ \\
\hline \multicolumn{10}{|l|}{ Preconditioner } \\
\hline Temperature $\left({ }^{\circ} \mathrm{C}\right)$ & 85.6 & 84.1 & 84.1 & 82.9 & 84.3 & 0.48 & 0.616 & 0.522 & 0.188 \\
\hline Output moisture (\%) & 27.7 & 26.7 & 27.9 & 27.0 & 28.3 & 0.004 & 0.675 & 0.102 & 0.812 \\
\hline Output mass (as-fed, kg/h) & 181.9 & 168.9 & 154.3 & 166.1 & 164.6 & 3.01 & 0.465 & 0.136 & 0.007 \\
\hline Starch gelatinization (\%) & 35.6 & 30.5 & 31.6 & 29.9 & 33.9 & 1.07 & 0.572 & 0.124 & 0.431 \\
\hline \multicolumn{10}{|l|}{ Extruder } \\
\hline Engine amperage (A) & 42.1 & 41.0 & 41.0 & 45.9 & 40.9 & 0.49 & $<0.001$ & $<0.001$ & 0.936 \\
\hline Die temperature $\left({ }^{\circ} \mathrm{C}\right)$ & 125.8 & 126.3 & 118.7 & 123.9 & 124.9 & 1.16 & 0.443 & 0.170 & 0.314 \\
\hline Die pressure (bar) & 61.7 & 53.4 & 52.5 & 56.2 & 60.2 & 1.57 & 0.110 & 0.569 & 0.047 \\
\hline Output mass (as-fed, kg/h) & 170.4 & 152.0 & 141.3 & 150.0 & 152.0 & 4.03 & 0.479 & 0.237 & 0.046 \\
\hline \multicolumn{10}{|l|}{ Energy balance (kW-h/t) } \\
\hline $\mathrm{SME}^{\mathrm{f}}$ & 14.1 & 13.4 & 22.4 & 26.8 & 20.2 & 1.47 & $<0.001$ & $<0.001$ & $<0.001$ \\
\hline STE $^{g}$ & 61.0 & 104.2 & 119.3 & 64.8 & 80.4 & 11.46 & 0.006 & 0.065 & 0.054 \\
\hline $\mathrm{TSE}^{\mathrm{h}}$ & 75.1 & 117.6 & 141.7 & 91.6 & 100.6 & 11.74 & 0.010 & 0.057 & 0.025 \\
\hline STE:SME & 4.32 & 7.76 & 5.30 & 2.42 & 3.98 & 0.60 & $<0.001$ & 0.589 & 0.746 \\
\hline \multicolumn{10}{|l|}{ Kibble traits (After Dryer) } \\
\hline Starch gelatinization (\%) & 92.8 & 93.8 & 94.6 & 91.9 & 94.0 & 0.48 & 0.673 & 0.051 & 0.545 \\
\hline Piece density $\left(\mathrm{kg} / \mathrm{m}^{3}\right)$ & 0.37 & 0.38 & 0.36 & 0.45 & 0.41 & 0.008 & $<0.001$ & 0.018 & 0.103 \\
\hline Radial expansion rate & 4.1 & 2.9 & 3.0 & 2.8 & 3.1 & 0.04 & 0.578 & 0.701 & 0.008 \\
\hline Specific length $(\mathrm{mm} / \mathrm{g})$ & 47.4 & 57.0 & 58.7 & 51.4 & 51.7 & 0.69 & $<0.001$ & 0.317 & $<0.001$ \\
\hline Cutting force (kg.f) & 2.4 & 4.0 & 4.1 & 3.4 & 3.1 & 0.06 & $<0.001$ & 0.2122 & $<0.001$ \\
\hline
\end{tabular}

a $\mathrm{CO}=$ control food, without added fiber source, $\mathrm{SF}_{\mathrm{L}}=$ sugarcane fiber, large particle; $\mathrm{SF}_{\mathrm{S}}=$ sugarcane fiber, small particles; $\mathrm{WB}_{\mathrm{L}}=$ wheat bran, large particles; $\mathrm{WB}_{\mathrm{S}}=$ wheat bran, small particles.

b $\mathrm{SEM}=$ standard error of the mean $(n=40)$.

c Sugarcane fiber $\left(\mathrm{SF}_{\mathrm{L}}+\mathrm{SF}_{\mathrm{S}}\right)$ versus wheat bran $\left(\mathrm{WB}_{\mathrm{L}}+\mathrm{WB}_{\mathrm{S}}\right)$.

d Large fiber particles $\left(\mathrm{SF}_{\mathrm{L}}+\mathrm{WB}_{\mathrm{L}}\right)$ versus small fiber particles $\left(\mathrm{SF}_{\mathrm{S}}+\mathrm{WB}_{\mathrm{S}}\right)$.

e Control (CO) versus fiber supplemented foods $\left(\mathrm{SF}_{\mathrm{L}}+\mathrm{SF}_{\mathrm{S}}+\mathrm{WB}_{\mathrm{L}}+\mathrm{WB}_{\mathrm{S}}\right)$.

f $\mathrm{SME}=$ specific mechanical energy.

g STE $=$ specific thermal energy.

h $\mathrm{TSE}=$ total specific energy

i $\mathrm{n}=20$ kibbles per food.

particle size fibers $(P<0.001)$. Pressure at die was lower for fiber supplemented foods than for CO diet $(P=0.046)$. Extruder output mass varied according to the preconditioner output mass, with a higher value for the $C O \operatorname{diet}(\mathrm{P}=0.046)$ compared to the other treatments. SME input was higher for fiber supplemented foods compared to CO diet, also higher for wheat bran compared to sugarcane foods and for large particles compared to small particle fibers $(\mathrm{P}<0.001)$. Fiber supplemented foods had higher STE input than CO although the contrast was not statistically significant, and STE for the foods with sugarcane fiber was higher as compared to the wheat bran foods $(P=0.006)$. These variations resulted in higher TSE addition for the fiber supplemented foods than for the CO diet $(P=0.025)$, and higher TSE $(P=0.01)$ and STE:SME ratio $(P<0.001)$ for sugarcane than wheat bran supplemented foods. Regarding kibble traits, foods with small particle size fiber tended to had higher starch gelatinization than large particle size fiber foods $(P=0.051)$. Piece density was higher for the wheat bran than for sugarcane fiber foods, and for large fiber particle than for small fiber particle foods $(\mathrm{P}<0.02)$. Fiber inclusion reduced the kibble radial expansion compared to the $\mathrm{CO} \operatorname{diet}(\mathrm{P}=0.008)$. Longitudinal expansion (specific length) was increased after fiber addition to foods $(\mathrm{P}<0.001)$, and was higher for sugarcane in comparison with wheat bran foods $(\mathrm{P}<0.001)$. Fiber inclusion resulted in a significant increase on cutting force $(\mathrm{P}<0.001)$ compared to $\mathrm{CO}$ diet, and this was higher for the sugarcane than for wheat bran foods $(\mathrm{P}<0.001)$. The internal and external pictures of the kibbles produced in treatment 2 are shown in Fig. 2. The cellular structure of the $\mathrm{CO}$ and the foods produced with small particle fibers $\left(\mathrm{SF}_{\mathrm{S}}\right.$ and $\mathrm{WB}_{\mathrm{S}}$ ) was composed of bigger cells compared to large particle fiber foods $\left(\mathrm{SF}_{\mathrm{L}}\right.$ and $\left.\mathrm{WB}_{\mathrm{L}}\right)$. The percentage of cell area in relation to total kibble diameter area was $15.6 \%$ for $\mathrm{CO}, 13.2 \%$ for $\mathrm{SF}_{\mathrm{L}}, 14.6 \%$ for $\mathrm{SF}_{\mathrm{S}}, 17.0 \%$ for $\mathrm{WB}_{\mathrm{L}}$, and $16.1 \%$ for $\mathrm{WB}_{\mathrm{S}}$. There were no apparent differences on pore formation on the kibble surface among treatments.

\section{Discussion}

This study evaluated the effect of the type and particle size of fiber sources on extrusion parameters of dog foods. Although independent processing variables were kept constant, fluctuations in water and steam injection and raw material feed rate were noted, which in turn could have impacted dependent variables such as the preconditioner temperature, output moisture and output mass as was noted especially for treatment 1 . The reductions in moisture and temperature could be related to a reduced capacity of steam absorption of the dough after guava fiber inclusion. It is possible that the fiber deflected the steam, reducing its condensation on the dough, as discussed by Robin et al. (2012). In treatment 2 was observed a tendency 

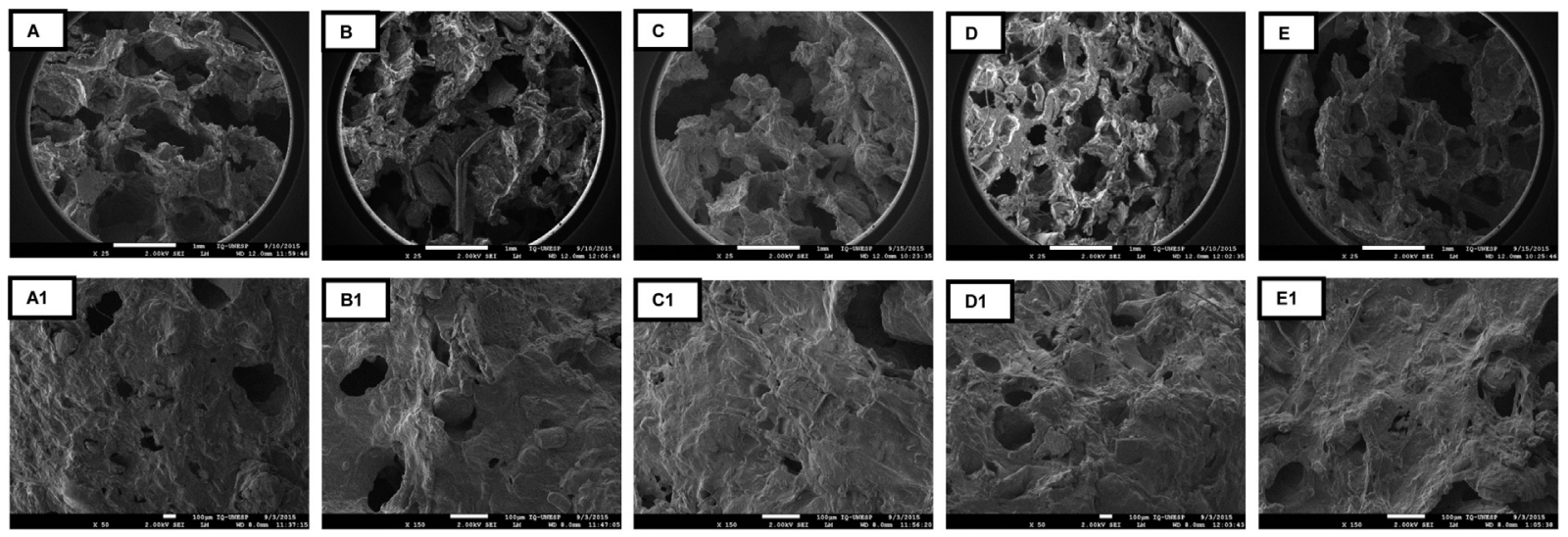

Fig. 2. Scanning electron micrograph of kibbles produced with different types and particle sizes of fiber on experiment 2. A, B, C, D, and E correspond to the internal area of the $\mathrm{CO}, \mathrm{SF}_{\mathrm{L}}, \mathrm{SF}_{\mathrm{S}}, \mathrm{WB}_{\mathrm{L}}, \mathrm{WB}_{\mathrm{S}}$ foods, respectively. Increase of $25 \times . \mathrm{A} 1, \mathrm{~B} 1, \mathrm{C} 1, \mathrm{D} 1$, and E1 correspond to the external surface of the $\mathrm{CO}, \mathrm{SF}$, $\mathrm{SF}_{\mathrm{S}}, \mathrm{WB}_{\mathrm{L}}, \mathrm{WB}_{\mathrm{S}}$ foods, respectively. Increase of $50 \times . \mathrm{CO}=$ control food, without added fiber source; $\mathrm{SF}_{\mathrm{L}}=\mathrm{sug}_{\mathrm{g}} \mathrm{rrcane}$ fiber, large particle; $\mathrm{SF}_{\mathrm{S}}=\mathrm{sugarcane}$ fiber, small particles; $\mathrm{WB}_{\mathrm{L}}=$ wheat bran, large particles; $\mathrm{WB}_{\mathrm{S}}=$ wheat bran, small particles

for lower preconditioner moisture for the large particle size fibers, reinforcing this hypothesis and suggesting that the fiber structure might play an important role for this effect. However, other observations later in this section related to STE input strongly refute this hypothesis.

Fiber had a larger and more discernible impact on processing due to other effects, that of lowering the raw material throughput into the preconditioner and also increasing resistance of the dough to flow inside the extruder. This could explain the differences in extruder amperage, temperature and pressure shown on treatment 1, and also increase in SME input for fiber supplemented foods in both treatments 1 and 2. Altan et al. (2008), Upadhyay et al. (2010), and Karkle et al. (2012a) previously demonstrated this effect of fiber in extruded foods for humans. The increased resistance to flow can be mostly attributed to the non-plastic and rigid nature of fiber as opposed to starch and other components in the food that are thermoplastic in nature and flow on application of pressure and heat. It is possible that reduction in the available water during extrusion when fiber is added to the recipe might have a role as well, thus reducing dough fluidity (Hill, 2003). Consistently higher STE was observed for foods supplemented with fiber in both treatments 1 and 2 , although that did not lead to increase in preconditioner temperature. This is possibly due to lower raw material throughput and/or greater steam or moisture absorption capacity of fiber and contradicts the earlier assertion that fiber could act to deflect the steam. However the higher STE did not lead to greater preconditioning temperatures, perhaps due to the higher heat capacity of fiber components that rest of the recipe. The role of fiber in pet food processing has not been studied previously, so future experiments will need to be conducted to further test these competing hypotheses.

Wheat bran and sugarcane fiber differ regarding their influence on processing traits. Wheat bran inclusion resulted in higher SME implemented, suggesting a higher resistance to flow in comparison with sugarcane fiber foods. An effect of fiber particle size was also observed, but only the $\mathrm{WB}_{\mathrm{L}}$ resulted in increased $\mathrm{SME}$, and no differences were seen between $\mathrm{SF}_{\mathrm{L}}$ and $\mathrm{SF}_{\mathrm{S}}$. These differences are likely related to particular physical characteristics and influences of each ingredient on the flow dynamic inside the extruder. The large wheat bran particle might have a high capacity of water binding, or induce a higher shear of the dough against the screw and jacket surfaces, increasing the mechanical energy required to transport it along the extruder. To demonstrate this, however, no previous study was found on dog foods and a specific experimental design is needed to be conducted.

The increased mechanical energy consumption has implications on the production cost of the food, and signals a less efficient processing after fiber addition. The utilization of electric power increased $85 \%$ after $12 \%$ addition of guava fiber in treatment 1, and wheat bran and sugarcane inclusion resulted in a mean elevation of $22 \%$ in treatment 2 . The increase was particularly important for the $\mathrm{WB}_{\mathrm{L}}$, with a value $57 \%$ higher than for CO. These increases in electric power consumption add cost to the production of fiber supplemented foods, and alternatives to a more rational processing condition should be studied. In addition to high processing cost, the increase in shear usually results in higher equipment wear. This was not computed on the present study, but need to be considered when computing the actual producing cost.

Kibble macrostructure was worse for fiber-supplemented foods with reduced expansion observed in both treatments, showing the negative effects of fiber on kibble formation and macrostructure. A reduction in starch cooking was observed in treatment 1 with guava fiber addition, and in treatment 2 with large particle size fibers. The starch fraction works as a thermoplastic polymer during extrusion. When water, energy, and time are sufficient in the processing, the starch granule loses its crystallinity, swells, and disrupts, forming an amorphous mass that binds all food components forming a continuous structure (Ding et al., 2005). Although energy implementation was higher for fiber supplemented foods, possibly the higher heat capacity of fiber in combination with binding of water could explain the lower starch gelatinization and poor kibble expansion for fiber supplemented foods in both treatment. Limitation on available water for starch cooking with fiber inclusion has been reported previously (Hill, 2003; Nelson, 2001). It is possible that the added fiber retained the water 
(Santos et al., 2008; Khanna and Tester, 2006), that then became less available for hydration, dough lubrication, and starch gelatinization.

High extrudate density with a shift toward longitudinal instead of radial expansion after fiber inclusion were observed for kibbles in treatment 2 and especially sugarcane fiber, but not in treatment 1 . This effect was already demonstrated after cellulose inclusion (Chinnaswamy and Hanna, 1991). The difference between the two treatments might be due to the nature of the fiber sources, which in case on guava fiber is angiosperm pericarp and in the case of sugar cane fiber is filamentous that promotes expansion in the longitudinal direction. Usually fiber particles also result in the formation of kibbles with small size and thicker cell walls (Robin et al., 2012). Imaging from the foods of the present study suggest that this is the case with high guava fiber and large particle size fiber inclusion, although this was only qualitatively evaluated. These structural changes could be responsible for the increased of kibble hardness (cutting force) with fiber addition. The higher cutting force is explained by the smaller cells with thicker walls, and by the strengthen effect of the fiber particles against the rupture of the molten starch mass. Thus fiber has significant effects on kibble structure. As discussed earlier, fiber effect in expansion and cell formation has been also attributed to its water binding capability (Moraru and Kokini, 2003; Jin et al., 1994; Camire and King, 1991). In addition, due to its structure, fiber can conduct the water vapor out of the kibble, reducing the flash off effect on cell formation (Lue et al., 1991; Robin et al., 2012), directly affecting expantion. Differences between the effect of wheat bran and sugarcane on kibble formation were also noted, with sugarcane inclusion resulting in lower piece density and higher specific length and cutting force. This means that sugarcane fiber induce higher longitudinal expansion, with lighter and harder kibbles than wheat bran. This diverse structure forming traits should be explored in specific foods when differences in density or specific influences on chewing dynamics are of interest. Regarding particle size, the finely grind fibers favoring formation of kibbles with lower piece density, signaling that fiber particle reduction might be a means of increase kibble expansion.

Several implications for this interference of fiber addition on expansion, cell structure formation and increase in hardness should be considered. Absorption of fat added by surface coating could be less efficient in fiber enriched foods. The lesser internal open space and external porous may impede the internal migration of fat, which will stay on surface. Fat distribution on kibbles are important for good food palatability, and a worse coating efficiency could reduce food acceptance by dogs. In addition, fat which remains on surface can migrate to the package, interfering on the nutrient content of the diet. Higher residence time on coating equipment, or even special coating systems with vacuum may be required for high fat addition, and this consideration is advisable for pet food companies doing high fiber foods.

As studies in dogs was not localized, in order to understand the possible implications of extrudate macrostructure on palatability, the foods from the present study were evaluated by an expert human panel to describe their sensory traits (Koppel et al., 2014). The physical attributes fracturability and initial crispness were different for CO than fiber supplemented foods. These changes in kibble texture may affect acceptability of the food by the dogs, although there are very few studies that evaluate the influence of the physical attributes of the kibble on canine diet palatability. It is possible that these physical alterations change the mastication kinetics or sensation, altering the acceptability of the food for dogs. The interference of fiber supplementation on chewing sensation, reducing food acceptance is well described in human beings (Karkle et al., 2012a; Martin et al., 2013). Due this, it should take into account that a low acceptance of a fiber-supplemented diet could be related with the taste or flavor of the ingredient, but also due the fiber source effect on the extrusion and kibble macrostructure.

Finally, taking into consideration the important increase on electric energy consumption, reduction on starch cooking, and worsen kibble formation, fiber addition to dog food recipes may substantially reduce the efficiency of the extrusion process. Studies to achieve better processing conditions, which could promote reductions on the electric energy required, and improve starch cooking and kibble formation are important.

\section{Conclusions}

The addition of fiber sources to dog food formulations increases electric energy required to extrude, and may reduce starch cooking and kibble expansion, leading to the production of denser and harder kibbles. Fiber type can also have a strong influence on expansion, with filamentous fiber promoting longitudinal expansion and thus lower piece density.

\section{Acknowledgments}

The authors acknowledge the financial and technical support of Guabi PetCare to the Laboratory of Research in Nutrition and Nutritional Diseases of Dogs and Cats "Prof. Dr. Flávio Prada", to Dilumix, Leme, SP, Brazil for the donation of the fiber sources and the partial financial support of the study, and Manzoni Industrial Ltda, Campinas, SP, Brazil for the extruder.

\section{References}

Altan, A., Mccarthy Kathryn, L., Maskan, M., 2008. Evaluation of snack foods from barley-tomato pomace blends by extrusion processing. J. Food Eng. 84, 231-242.

AOAC, 1995. Official Methods of Analysis, 16th ed. Assoc. Off. Anal. Chem., Washington DC.

Baik, B.K., Powers, J., Nguyen, L.T., 2004. Extrusion of regular and waxy barley flours for production of expanded cereals. Cereal Chem. 81, 94-99. 
Boac, J.M., Maghirang, R.G., Casada, M.E., Wilson, J.D., JUNG, Y.S., 2009. Size distribution and rate of dust generated during grain elevator handling. Appl. Eng. Agric. 25, 533-541.

Brennan, M.A., Merts, I., Monro, J., Woolnough, J., Brennan, C.S., 2008. Impact of guar gum and wheat bran on the physical and nutritional quality of extruded breakfast cereals. Starch 60, 248-256.

Camire, M.E., King, C.C., 1991. Protein and fiber supplementation effects on extruded cornmeal snack quality. J. Food Sci. 56, 760-763.

Challacombe, C.A., Seetharaman, K., Duizer, L.M., 2011. Sensory characteristics and consumer acceptance of bread and cracker products made from red or white wheat. J. Food Sci. 76, 337-346.

Chinnaswamy, R., Hanna, M.A., 1991. Physicochemical and macromolecular properties of starch-Cellulose fiber extrudates. Food Struct. 10 (3) (Article 6).

Ding, Q.B., Ainsworth, P., Tucker, G., Marson, H., 2005. The effect of extrusion conditions on the physicochemical properties and sensory characteristics of rice-expanded snacks. J. Food Eng. 66, 283-289.

FEDIAF, 2013. Nutritional Guidelines for Complete and Complementary Pet Food for Cats and Dogs. European Pet Food Industry Federation, Brussels, Belgium, www.fediaf.org/.../Nutritional_guidelines.pdf (accessed July 2015).

Fischer, M.M., Kessler, A.M., Sá, L.R.M., Vasconcellos, R.S., Roberti Filho, F.O., Nogueira, S.P., Oliveira, M.C.C., Carciofi, A.C., 2012. Fiber fermentability effects on energy and macronutrient digestibility, fecal parameters, postprandial metabolite responses, and colon histology of overweight cats. J. Anim. Sci. 90, 2233-2245.

Griffin, R.W., 2003. Section IV: palatability. In: Kvamme, J.L., Phillips, T.D. (Eds.), Petfood Technology. , 1st ed. Watt Publishing Co., Mt Morris, IL, USA, pp. $176-193$.

Hendrix, D.L., 1993. Rapid extraction and analysis of nonstructural carbohydrates in plant tissue. Crop Sci. 25, 1306-1311.

Hill, D.A., 2003. Fiber, texturized protein and extrusion. In: Kvamme, J.L., Phillips, T.D. (Eds.), Petfood Technology. Watt publishing, Mount Morris, IL, pp. $361-365$.

Jin, Z., Hsieh, F., Huff, E.E., 1994. Extrusion cooking of corn meal with soy fiber, salt, and sugar. Cereal Chem. 71 (3), $227-234$.

Karkle, E.L., Alavi, S., Dogan, H., 2012a. Cellular architecture and its relationship with mechanical properties in expanded extrudates containing apple pomace. Food Res. Int. 46, 10-21.

Karkle, E.L., Keller, L., Dogan, H., Alavi, S., 2012b. Matrix transformation in fiber-added extruded products: impact of different hydration regimens on texture, microstructure and digestibility. J. Food Eng. 108, 171-182.

Kawauchi, I.M., Sakomura, N.K., Vasconcellos, R., S, de-Oliveira, L.D., Gomes, M.O.S., Loureiro, B.A., Carciofi, A.C., 2011. Digestibility and metabolizable energy of maize gluten feed for dogs as measured by two different techniques. Feed Sci Technol. 169, 96-103.

Khanna, S., Tester, R., 2006. Influence of purified konjac glucomannan on the gelatinisation and retrogradation properties of maize and potato starches Food Hydrocolloids 20 (5), 567-576.

Koppel, K., Gibson, M., Alavi, S., Aldrich, G., 2014. The effects of cooking process and meat inclusion on pet food flavor and texture characteristics. Animals 4, 254-271.

Koppel, K., Monti, M., Gibson, M., Alavi, S., Donfrancesco, B., Carciofi, A.C., 2015. The effects of fiber inclusion on pet food sensory characteristics and palatability. Animals 5, 110-125.

Lue, S., Hsieh, F., Huff, H.E., 1991. Extrusion cooking of corn meal and sugar beet fiber: effects on expansion properties, starch, gelatinization, and dietary fiber content. Cereal Chem. 68, 227.

Martin, C., Chiron, H., Issanchou, S., 2013. Impact of dietary fiber enrichment on the sensory characteristics and acceptance of French baguette. J. Food Qual. 36, 324-333.

Mendonça, S., Grossmann, M.V.E., Verhé, R., 2000. Corn bran as a fibre source in expanded snacks. Lebenson Wiss Technol. 33, $2-8$.

Moraru, C.I., Kokini, J.L., 2003. Nucleation and expansion during extrusion and microwave heating of cereal foods. Compr. Rev. Food Sci. Food Saf. 2, 120-138.

Nelson, A.L., 2001. High-fiber Ingredients. Eagan Press, St. Paul, Minnesota, USA, pp. 45-62.

Riaz, M.N., 2000. Extruders in food alications. In: Riaz, M.N. (Ed.), Introduction to Extruders and Their Principles. CRC Press, pp. 1-23.

Riaz, M.N., 2007. Extruders and Expanders in Pet Food, Aquatic and Livestock Feeds. Agrimedia, Clenze (pp. 400).

Robin, F., Schuchmann, H.P., Palzerc, S., 2012. Dietary fiber in extruded cereals: limitations and opportunities. Trends Food Sci. Technol. $28,23-32$.

Sá, F.C., Vasconcellos, R.S., Brunetto, M.A., Roberti Filho, F.O., Gomes, M.O.S., Carciofi, A.C., 2013. Enzyme use in kibble diets formulated with wheat bran for dogs: effects on processing and digestibility. J. Anim. Physiol. Anim. Nutr. 97, 51-59.

SAS Institute, 2008. SAS 9.1 User's Guide. SAS Institute Inc., Cary, NC.

Santos, E., Rosell, C.M., Collar, C., 2008. Gelatinization and retrogradation kinetics of high-fiber wheat flour blends: a calorimetric approach. Cereal Chem. $85(4), 455-463$.

Upadhyay, A., Sharma, H.K., Sarkar, B.C., 2010. Optimization of carrot pomace powder incorporation on extruded product quality by response surface methodology. J. Food Qual. 33, 350-369.

Van Soest, P.J., Robertson, J.B., Lewis, B.A., 1991. Methods for dietary fiber, neutral detergent fiber and non-starch polysaccharides in relation to animal nutrition. J. Dairy Sci. 74, 3583-3597.

Yağci, S., Gögüüs, F., 2008. Response surface methodology for evaluation of physical and functional properties of extruded snack foods developed from food-by-products. J. Food Eng. 86, 122-132. 